\title{
Detection of pneumocystis DNA in nasopharyngeal aspirates of leukaemic infants with pneumonia
}

\author{
C G M Richards, A E Wakefield, C D Mitchell
}

\begin{abstract}
The technique of polymerase chain reaction was used to detect Pneumocystis carinii DNA in nasopharyngeal secretions of three infants with leukaemia who had the clinical features of $P$ carinii pneumonia. The use of this non-invasive technique allowed the early diagnosis and treatment of these infants whose protocols did not include the use of prophylactic co-trimoxazole

(Arch Dis Child 1994; 71: 254-255)
\end{abstract}

The diagnosis of Pneumocystis carinii pneumonia in childhood has, in the past, usually depended on bronchoscopic or non-bronchoscopic alveolar lavage to identify $P$ carinii by histochemical staining in the lower airway secretions. The technique of polymerase chain reaction has been shown to detect $P$ carinii DNA effectively in upper airway secretions of infected adult patients. ${ }^{12} \mathrm{We}$ describe the use of polymerase chain reaction in the detection of $P$ carinii DNA in nasopharyngeal aspirates from three infants, one with acute myeloid leukaemia (AML) and two with acute lymphoblastic leukaemia (ALL), who developed clinical features of $P$ carinii pneumonia during treatment.

\section{Patients}

The patient details are shown in the table. Each patient developed acute respiratory distress in the early stages of chemotherapy, during a time of profound neutropenia (neutrophil count $<0.5 \times 10^{9} / 1$ ). The chest radiographs showed diffuse bilateral opacification consistent with interstitial pneumonia. Nasopharyngeal secretions were then collected.

\section{Methods}

DNA EXTRACTION

Samples were treated with proteinase $K$, $1 \mathrm{mg} / \mathrm{ml}$ final concentration (Boehringer Mannheim) in the presence of $10 \mathrm{mM}$ EDTA, pH 8.0 and $0.5 \%$ sodium dodecyl sulphate, at $50^{\circ} \mathrm{C}$ for up to 18 hours. The samples were extracted with phenol:chloroform:isoamyl alcohol, and the DNA in the sample was recovered using a DNA binding resin (Magic DNA clean-up system, Promega), eluted in $50 \mu \mathrm{l}$ sterile distilled water and stored frozen at $-20^{\circ} \mathrm{C}$.
DNA AMPLIFICATION

DNA amplification was carried out on the samples using the polymerase chain reaction, with the $P$ carinii specific primers pAZ102-H and pAZ102-E. ${ }^{2}$ The amplification reaction mixture contained $50 \mathrm{mM}$ potassium chloride, $10 \mathrm{mM}$ Tris, $\mathrm{pH} 9 \cdot 0,0 \cdot 1 \%$ Triton $\mathrm{X}-100$, $3 \mathrm{mM}$ magnesium chloride, $400 \mu \mathrm{M}$ dNTPs (each of the four deoxyribonucleoside triphosphates, Boehringer Mannheim), $1 \mu \mathrm{M}$ oligonucleotide primer and 0.025 units $/ \mu 1$ of Taq polymerase (Promega), with denaturation at $94^{\circ} \mathrm{C}$ for $1.5 \mathrm{~min}$, annealing at $55^{\circ} \mathrm{C}$ for 1.5 min, and extension at $72^{\circ} \mathrm{C}$ for $2.0 \mathrm{~min}$ for 40 cycles. Negative controls, with no added template, were tested with each clinical sample. The amplification products underwent electrophoretic separation in $1.5 \%$ agarose gels, and the presence of a $P$ carinii specific band ( 346 base pairs) was detected by visualisation with ultraviolet light after ethidium bromide staining.

\section{Results}

The polymerase chain reaction was carried out on total DNA extracted from the nasopharyngeal secretions from each patient and resulted in the synthesis of a P carinii specific amplification product, detected on ethidium bromide stained gels. Only $50 \mu \mathrm{l}$ of secretions were required for this test. The detection of $P$ carinii DNA allowed the non-invasive confirmation of the clinical diagnosis of $P$ carinii pneumonia. However, in one infant (patient 1) who required ventilation, $P$ carinii was also identified by microscopy after methamine silver staining of a sample of bronchoscopic lavage fluid. The three patients responded to high dose intravenous co-trimoxazole, in a manner consistent with the diagnosis of $P$ carinii pneumonia.

\section{Discussion}

In the three infants with the clinical features of $P$ carinii pneumonia, a test using the

Patient details

\begin{tabular}{llcl}
\hline $\begin{array}{l}\text { Patient } \\
\text { No }\end{array}$ & Diagnosis & $\begin{array}{l}\text { Age } \\
\text { (months) }\end{array}$ & Chemotherapy received \\
\hline 1 & ALL & 7 & $\begin{array}{l}\text { MRC infant ALL protocol, } \\
\text { week 8 } \\
\text { MRC infant ALL protocol, } \\
\text { week 7 }\end{array}$ \\
3 & ALL & 11 & ADE 10+3+5*, ADE 8+3+5*
\end{tabular}

^ADE = cytarabine, daunorubicin, and etoposide. Numbers refer to days of treatment. 
polymerase chain reaction showed $P$ carinii DNA to be present in their nasopharyngeal secretions. It is increasingly recognised that lower airway infection with $P$ carinii is accompanied by the presence of the organism in upper airway secretions. ${ }^{3}$ Access to lower airway secretions may be limited in children whose clinical state does not warrant intubation and ventilation. Bronchoscopic lavage may lead to respiratory deterioration in a patient already in respiratory distress. The alternative of induced sputum is impractical in infants and young children. Therefore, identification of $P$ carinii in nasopharyngeal secretions may provide a simple and noninvasive means of diagnosis. A case report has previously described the identification of $P$ carinii, using a fluorescent antibody technique, in the nasopharyngeal secretions of an HIV positive infant who had signs consistent with $P$ carinii pneumonia. ${ }^{4}$

The polymerase chain reaction technique is highly specific and sensitive for $P$ carinii DNA and has been shown to be diagnostically useful in bronchoalveolar lavage and induced sputum samples in adults with pneumonia. ${ }^{12}$ Combining the sensitivity and specificity of $P$ carinii DNA detection by the polymerase chain reaction with this non-invasive sample method offers a potentially valuable diagnostic tool that needs to be evaluated in a large group of children with suspected $P$ carinii pneumonia.

None of the infants was on prophylactic co-trimoxazole at presentation. The current AML regimen does not prescribe it, nor is it included until week 16 of the current MRCUKALL infant protocol once the late intensification has been completed, on the basis of the small risk to patients. The occurrence of pneumocystis pneumonia in infants early in their chemotherapy regimen suggests that infants with leukaemia are at particular risk of $P$ carinii pneumonia and should therefore receive prophylactic co-trimoxazole early in their treatment.

This work was supported by the Royal Society (AEW).

1 Wakefield AE, Pixley FJ, Banerii S, et al. Detection of Pneumocystis carinii with DNA amplification. Lancet 1990; 336: 451-3.

2 Wakefield AE, Guiver L, Miller RF, Hopkin IM. DNA amplification on induced sputum samples for diagnosis of amplification on induced sputum samples for diagnosis of Pneumocyst 1378 -9.

3 Wakefield AE, Miller RF, Guiver LA, Hopkin JM. Oropharyngeal samples for detection of Pneumocystis carinii by DNA amplification. $Q \mathcal{f}$ Med 1993; 86: 401-6.

4 Hague RA, Burns SE, Mok JYQ Yap PL. Diagnosis of Pneumocystis carinii pneumonia from non-invasive sampling of respiratory secretions. Arch Dis Child 1990; 65: 1364-5. 